UDC: 821.134.1.09-342 Herra R. A.

DOI: https://doi.org/10.18485/beoiber.2017.1.7

\author{
Giuseppe Gatti Riccardi ${ }^{1}$ \\ Universitá degli Studi Guglielmo Marconi \\ Universitá degli Studi della Tuscia \\ Italia
}

\title{
IRONÍA Y HUMOR NEGRO EN EL REINO ANIMAL: LA DIVINA CHUSMA DE RAFAEL ÁNGEL HERRA, O UNA REVISITACIÓN DE LA FÁBULA TRADICIONAL
}

\section{Resumen}

El presente estudio se centra en el análisis de la recopilación de fábulas La divina chusma, que el escritor y filósofo costarricense Rafael Ángel Herra (1943) ha publicado en 2011. Lo que se intentará demostrar es cómo el volumen enlaza con los modelos clásicos (Esopo, Fedro) y dieciochescos (La Fontanie, Iriarte, Samaniego), al tiempo que sugiere una revisitación del género según una línea paródica que no desdeña el uso de la ironía y del humor negro.

Para alcanzar nuestro objetivo, se propone en primer lugar una lectura desde la tradición del género de la fábula, haciendo alusión a los intertextos y a la función de la fábula en contextos históricos desde la época grecolatina hasta la etapa de la llustración. En cuanto a la teoría que funciona de soporte a la investigación, se propone un engarce de estudios canónicos (como los de Vladimir Propp) con algunas teorías literarias de interés actual, como las reflexiones de Omar Calabrese acerca de la recuperación de productos estéticos y artísticos del pasado, o los estudios de David Le Breton sobre la necesidad del ser humano de sustraerse a la presión social (con aplicación, claro está, al mundo animal), sin descuidar las investigaciones de Bruno Bettelheim sobre los significados psicoanalíticos de las fábulas.

Palabras clave: Rafael Ángel Herra, literatura costarricense contemporánea, La divina chusma, género de la fábula.

\section{IRONY AND BLACK COMEDY IN THE ANIMAL KINGDOM: LA DIVINA CHUSMA (THE DIVINE RABBLE) BY RAFAEL ÁNGEL HERRA, OR A REVISION OF THE TRADITIONAL FABLE}

\begin{abstract}
This study focuses on the analysis of the collection of fables La divina chusma, by the writer and philosopher Rafael Angel Herra (Costa Rica, 1943), published in 2011. We will try to demonstrate how the

1 giuseppe_gatti@hotmail.com, g.gatti@unimarconi.it
\end{abstract}


volume relates to the classical models (Aesop, Phaedrus) and to the ones from the $18^{\text {th }}$ century (La Fontaine, Iriarte, Samaniego), while it suggests a revisit to the genre from a parodic point of view that does not abstain from the use of irony and black humor.

To achieve our goal, we propose, at first, a reading from the tradition of the genre of the fable, through a study of intertexts and the role of the fable in historical contexts from the Greco-Roman era to the stage of the Spanish Ilustración. Regarding the theory that we use as a research support, we propose a link between consolidated literary theories (from Vladimir Propp) and other theories of current interest, such as Omar Calabrese's reflections on the recovery of aesthetic and artistic products of the past, or the studies of David Le Breton on the need of human beings to escape social pressure (with an application, of course, to the animal world), or - finally - Bruno Bettelheim's research into the psychoanalytic meanings of fables. fable.

Key words: Rafael Angel Herra, Costa Rican Contemporary Literature, La divina chusma, genre of

[...] que en estos versos trato / de daros un asunto Que instruya deleitando / los perros y los lobos, Los ratones y los gatos, / las zorras y las monas, Los ciervos y caballos / os han de hablar en verso, Pero con juicio tanto / que sus máximas sean Los consejos más sanos.

(Félix María Samaniego, Fábulas)

\section{I - Un género al servicio de la transmisión de una enseñanza moral}

Una definición exhaustiva del término "fábula" resulta problemática por el valor polisémico del término, tal como se desprende de la primera acepción que el DRAE propone, al definir la fábula como un ubreve relato ficticio, en prosa o verso, con intención didáctica o crítica frecuentemente manifestada en una moraleja final, y en el que pueden intervenir personas, animales y otros seres animados o inanimados" (DRAE). Dentro de esta ambigüedad descriptiva -que aúna didactismo y denuncia, prosa y versola fábula mantiene como componente esencial el del moralismo docente, que pone de relieve su intencionalidad didáctica ya desde la época griego-latina.

A lo largo del siglo XVIII, etapa histórica en que la orientación utilitaria de las artes se hace más patente, el género de la fábula vive un periodo de renovación y nuevo desarrollo gracias a las preocupaciones morales y a la búsqueda de una literatura didáctica que impregna los proyectos de reformas socio-culturales de los intelectuales ilustrados.

Durante el Siglo de las Luces, la tradición fabulística clásica, en particular la herencia de Esopo y de Fedro, es recuperada y adaptada al cronotopo concreto de la sociedad ilustrada, con la finalidad de ofrecer al público una obra que -dentro de la idea dominante del utilitarismo de la literatura- sea a la vez clara, sencilla y también instructiva. Si hay coincidencia sobre el valor de la fábula como instrumento para la 
transmisión de una enseñanza, la hay también acerca del rol de este sub-género como herramienta para transmitir al lector una serie de ejemplos que explican cómo tiene que ocurrir el desarrollo del ser humano a partir de modelos de la ficción; Bruno Bettelheim, en particular, subraya esta función de la fábula y advierte cómo

las fábulas tratan en forma literaria los problemas esenciales de la vida, sobre todo aquellos inherentes a la lucha para la consecución de la madurez. Alertan contra las consecuencias destructivas de la falta de desarrollo de niveles superiores de la personalidad [de los personajes] (Bettelheim 2015: 178)².

En el marco de esta reflexión que la fábula ha planteado sobre lo esencial de la existencia humana, un breve enfoque diacrónico sobre el género permite observar cómo ya en época clásica la fábula griega había recibido aportaciones temáticas procedentes de la fábula mesopotámica, la cual había influido también los textos escritos en la India: ambas tradiciones se vuelven a conectar en la etapa histórica que coincide con la llegada de Alejandro Magno a la península indiana.

A partir del breve reinado de Alejandro, la fábula griega ha seguido viva en la reelaboración de sus temas que se produjo en la tradición latina, y en la alta Edad Media (entre los siglos $\mathrm{IX}$ y $\mathrm{XI}$ ) tuvo un impacto cultural esencial al fundirse con la tradición popular de las varias regiones europeas y con la herencia latina. En ese periodo, tanto fábulas griegas como fábulas orientales traducidas al griego "penetraron desde Bizancio en la Europa latina, donde contrajeron una fecunda relación con la tradición latina antigua de la fábula, la tradición popular europea y la tradición cristiana” (Rodríguez Adrados, 1982: 651).

Cuando, a mediados del siglo XIII, se realizan las traducciones al castellano de recopilaciones de procedencia oriental como el Sendebar, el Calila y Dimna o el Panchatantra, la tradición medieval cristiana se enriquece de libros de apólogos y exempla, y se consolida la tendencia -ya bien presente en las fuentes clásicas- que sugiere a los autores la redacción de historias moralizadoras: una corriente que siguieron tanto Don Juan Manuel en El conde Lucanor (1330-1335), como el Arcipreste de Hita en El libro de buen amor (1330 o 1343) o -más de un siglo antes- Pedro Alfonso en su Disciplina clericalis, escrita en latín a comienzos del siglo XII.

Dentro de un género que iba consolidando su perfil aleccionador, la obra de relectura y revisión de los textos clásicos que en la segunda mitad del siglo XVII efectúa La

\footnotetext{
2 Se ha tenido acceso al ensayo de Bettelheim The use of enchantment. The meaning and importance of fairy tales a través de la versión italiana de su trabajo, titulada II mondo incantato. Uso, importanza $e$ sigificati psicoanalitici delle fiabe. El texto de la cita en la versión italiana que se ha utilizado es el siguiente: "Le fiabe trattano in forma letteraria i problemi basilari della vita, soprattutto quelli inerenti alla lotta per il conseguimento della maturitá. Essi mettono in guardia contro le conseguenze distruttive del mancato sviluppo di livelli superiori di personalitá".
} 
Fontaine (1621-1695) supone el surgimiento de una nueva fase histórica para la fábula: sus textos perpetúan la tradición medieval francesa del Roman de la Rose o de los sermones de Jacques de Vitry, y se componen de historias satíricas y cómicas sobre las costumbres y los hábitos de la sociedad, siempre procurando que los personajes fueran personificación de animales. La producción fabulística de La Fontaine representa una summa de la cultura latina y la griega, debido a la labor de traducción y adaptación de textos de la antigüedad clásica (no solo Esopo y Fedro, sino también Horacio, Tito Livio, y hasta cartas apócrifas de Hipocrates), al punto que todos los fabulistas de Europa

sufrieron su influencia, aun y sobre todo, cuando quisieron enfrentarse a él o superar su ejemplo. Por esta razón, al hablar de cualquier autor de fábulas, se le comparará enseguida con La Fontaine, para llegar invariablemente a la conclusión de que el autor de que se está tratando nunca llegó a la altura de su modelo (Cioranescu 1954: 201).

En la España de la llustración, el género fabulístico, después de un largo paréntesis de silencio (en el que solo se había manifestado de forma implícita en el teatro y en la novela picaresca), reaparece -como instrumento literario que revisita en clave neoclásica el objetivo horaciano del prodesse et delectare de la mano de Tomás de Iriarte (1750-1791) y de Félix María Samaniego (1745-1801), siendo este último quien importa a la península el modelo de "fábula moderna" recreado en Francia por La Fontaine.

Las fábulas contenidas en el volumen Fábulas literarias que Iriarte dio a imprimir en el año 1782 ofrecen al lector un motivo original por la época, puesto que hacen explícitas alusiones a cuestiones literarias y convierten a los animales que las protagonizan en un instrumento útil no solo para subrayar -según el esquema conceptual neoclásico- la necesidad de reglas (es decir, la rectificación de los presuntos "desvaríos" estéticos del Barroco), sino también para poner en evidencia vicios y valores que se observan en la vida de los mismos escritores. Los animales que aparecen en las fábulas interactúan entre sí o con seres humanos para que el lector reflexione sobre la urgencia de defender el castellano frente a la presión que los galicismo ejercen sobre el español ("Los dos loros y la cotorra"), o sobre la necesidad de desterrar toda improvisación del ejercicio de escribir, en pos de la adopción de un método y una regla ("El burro flautista”).

En cuanto a las Fábulas de Samaniego (1781 y 1784, el primero y el segundo volumen, respectivamente), es bien sabido que los dos tomos nacen con el objetivo de ser utilizados para la educación de los alumnos del Seminario de Vergara, del que el intelectual se había hecho cargo a partir de 1771): la mayoría de los motivos presentes ya estaban explicitados en los textos de Esopo y Fedro, más que en los exempla de la tradición medieval (influida por los apólogos orientales), puesto que Samaniego "no sigue la amplia tradición medieval. Sino que recurre [...] a autores que reconoce como maestros en el género; [...] Sus fábulas suponen una nueva versión del mundo de la fábula tradicional [...] llevada a cabo a través, fundamentalmente, del francés La Fontaine" (Sotelo 2012: 59-60). 
De nuevo, la fábula -por medio de una adaptación que no es una mera repetición del modelo clásico- utiliza a los animales para reflexionar críticamente sobre los vicios presentes en la sociedad de la época; la fábula "La zorra y el busto" denuncia los excesos de vanidad, así como "La cigarra y la hormiga" se ocupa de poner en tela de juicio la imprevisión y, de nuevo, la zorra es el animal elegido para criticar la prisa excesiva ("La zorra y las uvas").

Paralelamente a esta línea de denuncia de los vicios de la sociedad humana, Samaniego se sirve de los animales para que sean también los actores de parábolas políticas fundadas en la centralidad del rol didáctico de la literatura, en un siglo marcado precisamente por el "deseo de normas y organización, de asociación de individuos y trabajo colectivo, de control de ideas y abordaje de grandes empeños" (Alvar et al. 2011: 439). Fábulas como "El león y su ejército" conectan con esta búsqueda de la élite ilustrada y plantean la necesidad del esfuerzo colectivo, mientras otras como "El pastor y el filósofo" se centran en la alabanza de la razón y en celebrar la superioridad de la racionalidad y del intelecto frente a los contenidos librescos.

Más de doscientos treinta años después de la publicación de los volúmenes de Iriarte y Samaniego, la recopilación de las ciento y una fábulas de La divina chusma, que el escritor y filósofo costarricense Rafael Ángel Herra publicó en 2011, propone una revisitación del género que superpone el modelo clásico a la tradición dieciochesca española, y las moldea según un esquema formal denso de reflexiones irónicas y amargas sobre el ser humano3.

Con el objetivo de identificar la(s) categoría(s) de pertenencia de las fábulas de Herra dentro del subgénero fabulístico, cabe recuperar la clasificación ya canónica que primero Willhelm Wundt en Völkerpsychologie (1920) y después Vladimir Propp en Morfologija skazki (1969) proponen, y que puede resumirse según un esquema que identifica los siete ámbitos tipológicos siguientes: 1) cuentos-fábulas mitológicas; 2) cuentos maravillosos puros; 3) cuentos y fábulas biológicas; 4) fábulas puras sobre animales; 5) cuentos sobre "el origen"; 6) cuentos y fábulas humorísticas; 7) fábulas morales.

${ }^{3}$ Rafael Angel Herra es Doctor en Filosofía por la universidad alemana de Maguncia, miembro de número de la Academia Costarricense de la Lengua, ex catedrático y por muchos años Director de la Revista de Filosofía de la Universidad de Costa Rica. Ha sido profesor invitado en las Universidades de Bamberg y Giessen, además de ex embajador en Alemania y en la Unesco. Dentro de la amplia producción literaria de Herra, que incluye obras ensayísticas, textos para el teatro y poesía, nos limitaremos aquí a señalar sus textos pertenecientes al género narrativo en prosa. El primer libro de cuentos de Herra se publica en 1983 con el título de El soñador del penúltimo sueño. Siempre en la década de los ochenta ven la luz también otra recopilación de relatos Había una vez un tirano llamado Edipo y la novela La guerra prodigiosa, de 1986. En lo años noventa se publican las novelas El genio de la botella. Relato de relatos (1990) y Viaje al reino de los deseos (1992). En los primeros años del nuevo siglo ven la luz La divina chusma. 101 fábulas (2011), objeto de nuestro estudio en estas páginas, además de D. Juan de los manjares (novela, publicada en 2012), El ingenio maligno (también novela, del año 2014) y Artefactos, de 2016. 
Por sus características de reescritura paródica de textos clásicos protagonizados por animales con vicios y virtudes (pocas) de los seres humanos, podría considerarse La divina chusma como una recopilación que toma tanto de la categoría de las fábulas puras sobre animales como de las fábulas morales, con incursiones puntuales en la categoría de los cuentos y fábulas humorísticas, siendo el humor negro un sello distintivo presente en un alto porcentaje de los breves textos de Herra.

Al diálogo de Herra con la tradición fabulística clásica y con la dieciochesca española, y al uso del género no solo como herramienta de enseñanza sino también de reflexión paródica e introspectiva, dedicaremos las páginas del apartado que sigue.

\section{II - Un género al servicio de la transmisión de una enseñanza moral}

La divina chusma puede leerse como el resultado de una tendencia cultural que se relaciona con el término passe-par-tout que es la palabra "postmoderno". Aplicado a la literatura, el término -ya usado en exceso- alude a la existencia de ciertos productos artísticos que dejan de perseguir una línea de experimentación literaria, buscando en cambio un proceso de reelaboración de la herencia cultural del pasado; en la práctica, este ejercicio consiste en llevar adelante una tarea de deconstrucción del patrimonio de las letras y construir un producto que se presente al lector como un pastiche.

Las reflexiones propuestas por Jean-Francois Lyotard en su obra La condición posmoderna (1979) se centran en el nuevo estado de la cultura posterior a las transformaciones de las ciencias, de las artes, de la literatura y de los equilibrios socioeconómicos empezados a finales del siglo XIX, y sostienen la crisis de la narración; de ahí que, en palabras del mismo Lyotard, "podemos considerar posmoderna la incredulidad hacia las meta-narraciones" (Lyotard 1981: 78). En literatura, deconstruir y reelaborar el patrimonio literario preexistente no significa solo "ausencia de experimentación", sino también enjuiciar una cultura fundada en narraciones que se convierten en prescripciones.

No obstante, cabe observar cómo en los textos de ficción producidos en los últimos cuarenta años en el ámbito occidental, los productos reelaborados nacen no solo como resultado de una repetición más o menos mecánica y de una revisión (¿u optimización?) del "producto preexistente", sino que este trabajo de reelaboración produce a su vez una estética. Ya no tiene cabida la reflexión, en su momento muy generalizada, por la cual la repetición se percibe como polo opuesto de la originalidad y de la capacidad de "creación artística". Pierde vigencia la línea idealista que Benedetto Croce había propuesto en la segunda década del siglo pasado en su ensayo Estetica come scienza dell'espressione e linguistica generale: una línea que consideraba un artefacto una "obra de arte" solo en el caso en que fuera imposible "repetirle".

Sin embargo, la postura que idealiza la unicidad de la obra de arte ya se había empezado a derrumbar en la década de los setenta del siglo XX, a partir de la difusión de los llamados "múltiples", prácticas contemporáneas que acabaron definitivamente con la 
sacralidad del original. Al hecho de que muchas prácticas posmodernas exalten el uso de la cita y celebren el pastiche, se suma la evidente inadecuación del uso mismo del término "repetición", pues se trataría -desde una perspectiva actual- de un preconcepto ya anacrónico que impide reconocer el nacimiento de una nueva estética: la de la recuperación y remodelación de productos culturales del pasado según patrones conceptuales y estilísticos conformes con el tiempo presente.

En La divina chusma, Herra sí se acerca al género de la fábula bebiendo de las fuentes clásicas, de las creaciones solo en parte novedosas de La Fontaine, y de las adaptaciones político-didácticas de los ilustrados españoles, pero su aproximación a la fábula ocurre a través de una escritura que es esencialmente una parodia de todos estos referentes canónicos. El escritor costarricense mezcla ironía y humor negro, y su mensaje a menudo cáustico- se dirige a la representación de las conductas humanas, mediadas por el filtro del protagonismo animal ${ }^{4}$.

La racionalidad de los seres pertenecientes al reino animal se convierte en una herramienta al servicio de un objetivo: apelar dura y acertadamente a la dimensión emotiva de los lectores, haciendo que el público se tambalee entre la sonrisa y el asombro, transitando por momentos de reflexión trascendente (de entre los grandes misterios que se desentrañan cabe señalar, por ejemplo, el motivo por el que los cangrejos tienen una tenaza tan grande). No es casual, en este sentido, que el mismo Herra se exprese así acerca de sus propósitos al recopilar sus fábulas: "traté de que estas fábulas no tuvieran moraleja y que fuese el lector quien extrajera conclusiones, puesto que, de todas formas, la fábula no puede evitar fundarse en defectos y (alguna que otra) virtud humana" (Herra 2016: inédito) ${ }^{5}$.

Ahora bien, en este juego de espejos que Herra establece con los referentes modélicos del pasado, y que le permite a la vez desplegar la imaginación, la síntesis estilística y la observación de analogías entre seres humanos y animales, cabe una reflexión acerca de la estructura narratológica de la recopilación. Se trata de que desde hace tiempo la semiótica narrativa ha puesto en evidencia cómo en cada relato existen unas estructuras conceptuales que se depositan en lo más profundo del texto y se mantienen en un nivel más abstracto que el plano de lo que se narra. Las fábulas, por su misma finalidad de herramienta didáctica y moralizante, ofrecen al lector historias que

${ }^{4}$ En el prólogo que abre el libro, el narrador de las fábulas es un papagayo que apela a la colaboración del lector aludiendo explícitamente a la capacidad del público para discernir entre verdades y chismes dentro de lo narrado. Quien se ocupa de narrar decide actuar, en realidad, como un intermediario entre el reino animal y la dimensión de lo humano (el público de "señores y señoras"); así se expresa: "Los animales de ciencia, tan poco adictos a la maledicencia, debieron investigar ciertas historias controvertidas en el reino animal. Se las voy a referir, señoras y señores, aunque a los papagayos nos persiga el escarnio de los narradores, a quienes nadie les cree cuando dicen la verdad. [...] Transcribo aquí las historias. Lean ustedes y decidan por su cuentan (Herra 2011: 11).

${ }^{5}$ La cita forma parte de un intercambio de correos electrónicos que mantuve con el escritor a lo largo del mes de octubre de 2016 durante la fase de redacción del presente estudio. 
tienen diferentes niveles de profundidad estructural: a un nivel de discursividad se añade el nivel de la verdadera estructuración narrativa y sigue un tercero, más abstracto, que es el "fundamental". A medida que aumenta la profundidad de los niveles, se da un proceso de progresiva reducción de la complejidad a estructuras cada vez más elementales.

Esta jerarquización se puede aplicar a la "relectura" que Herra nos presenta, en el sentido de que las estructuras más elementares (es decir, los niveles más profundos, el mensaje último) son los que necesariamente se repiten. Así, según advierte Omar Calabrese, “i livelli piú profondi sono quelli che riducono la complessitá a strutture sempre piú elementari. Ebbene, il fatto che queste si ripetano diventa ovvio, e anzi conecessario alla teoria" (Calabrese 1987: 35).

Ahora bien, la estructura más elemental es donde reside el macro-mensaje, es decir, el de carácter más universal: si así lo entendemos, las ciento y una fábulas de Herra están protagonizadas por animales cuyo grado de humanización es en sí variable, pero sin dejar que el lector perciba en el fondo (o sea, en el nivel más profundo del texto) la presencia de un mensaje universal de reflexión -a veces crítica, otras amarga o solo enternecidasobre las dinámicas que guían las conductas y las formas de interacción de los seres humanos.

Hay humor negro y hay denuncia en los textos de Herra, y sin embargo, en su irónica observación de las conductas, la fijación de analogías que se crea a partir del juego de espejos, contempla también el análisis de las virtudes: el escritor costarricense se aleja del plano de la denuncia tout-court presente en las fábulas de Iriarte, y observa con un dejo de ternura a sus criaturas animales ( $y$ a sus espejos humanos), puesto que "con holgura y humor, estos cuentos breves construyen analogías entre acciones, costumbres, vicios y virtudes del homo sapiens y el animal sapiensin (Hernández 2011: en línea),

Una posible clasificación de las ciento y una fábulas incluidas en La divina chusma puede pasar por la identificación de tres macro-grupos temáticos que permitirían -sin pretensión de exhaustividad absoluta- la elaboración de un esquema así concebido:

a) fábulas que funcionan como parábolas de las dinámicas humanas de implicación en ejercicios y responsabilidades compartidos y colectivos;

b) fábulas que funcionan como expresión del deseo de alejamiento del mundo y/o de huida de sí mismos por parte de los protagonistas;

c) fábulas que funcionan como relatos de condena de toda forma de vanidad y envanecimiento.

La clasificación que se acaba de proponer intenta recuperar la lógica de ordenación planteada por Propp acerca de la necesidad de aproximarse al estudio del cuento y de la fábula examinando su estructura conceptual. No se trata de acercarse a la fábula desde la perspectiva de sus motivos, según las cualidades de sus protagonistas (qué raza de animal, en el caso de la fábula), según su cantidad (número de personajes y de héroes de cada relato) y según los objetos que manejan ${ }^{6}$, sino de un acceso al subgénero y a su

${ }^{6}$ La clasificación que toma en cuenta parámetros (denominados "motivos") como la cualidades de los protagonistas, su cantidad (número de personajes y de héroes de cada relato) y los objetos que manejan 
clasificación en el volumen de Herra, apuntando a definir las macro-estructuras conceptuales de sus fábulas.

De este modo, se identifican bloques de fábulas similares según el criterio de que "la seule étude qui puisse répondre à ces conditions est celle qui découvre les lois de la structure, et non celle qui présente un catalogue superficiel des procédés formels de l'art du conte" (Propp 2012: 25). Siguiendo este principio, y manteniendo la línea indicada por el escritor mismo, por la cual "cada característica animal (por comportamiento, por forma o función corporal) representa, por analogía, una conducta humana" (Herra 2016: inédito), en la sección que sigue examinaremos en detalle los tres puntos.

\section{III - El animal como espejo (poco deformado) de lo humano}

El objetivo de este apartado reside en examinar por separado las tres categorías que se acaban de identificar, empezando por las fábulas que funcionan como parábolas de las dinámicas humanas de implicación en ejercicios y responsabilidades compartidos y colectivos. El miedo de las responsabilidades colectivas representa uno de los rasgos característicos de la época contemporánea, marcada -a partir de los años ochenta del siglo XX-por la defintiva toma de conciencia del derrumbe de las utopías de esa centuria (la Revolución mexicana de 1910; la primera revolución estudiantil mundial en Argentina -el Cordobazo, de 1917; la Revolución de octubre en Rusia, siempre en 1917, la Revolución cubana de 1959). Sobre la base de la evidencia del fin de las esperanzas utópicas, Herra parece insistir en el miedo contemporáneo a la asunción de responsabilidades colectivas y plantea su denuncia de la desaparición del esfuerzo común desde la perspectiva de un humor amargo.

En sus fábulas, incluso un proyecto colectivo mínimo como el que emprenden las tres arañas protagonistas del cuento homónimo está destinado al fracaso: frente a la posibilidad de concentrar sus esfuerzos, combinar las telas que tejían y "componer una sola que les sirviera para cazar a todos los insectos de la tarde" (Herra 2011: 34), el desenlace se centra en la incapacidad para coordinar los esfuerzos: "se enredaron tanto que no solo se convirtieron en el hazmerreír del reino, sino que acabaron la jornada sin alimento alguno" (Herra 2011: 34).

Situaciones parecidas son las que se presentan en fábulas como "El orden de las hormigas" o "Los moscos"; en la primera, el narrador ironiza sobre la disciplina que rige el funcionamiento de los mecanismos internos a los hormigueros: "la disciplina llega a tal extremo que cuando una obrera envía una señal desde el final de la fila, el mensaje va pasando de una a otra hasta llegar al nido, donde lo escuchan los zánganos y la reina"

había sido propuesta en los años venite del siglo pasado por R.M. Volkov en Skazka. Rozyskanija po sjuzhetoslozheniju narodnoj skazki, tomo l. Gosizdat - Ukrainy (Odessa). 
(Herra 2011: 20). El humor cáustico que castiga toda suposición de eficiencia se hace manifiesto cuando el narrador nos informa de que "la desventaja del sistema es su lentitud. Pocas obreras han sobrevivido para contarlo" (Herra 2011: 20).

Del mismo modo, los moscos que protagonizan el cuento homónimo se entrenan sin detenerse nunca para dibujar en el aire, mientras están volando en grupo, unos "ochos" de forma perfecta. En este esfuerzo de coordinación compartido en el que pretenden exhibir la perfección de su vuelo sincronizado, llegan al punto en que ues tan inmenso, tan inconmensurable el placer de volar en forma tan precisa, que vuelan hasta morir" (Herra 2011: 67).

En todas las fábulas pertenecientes a este primer bloque, el autor dialoga con la tradición neoclásica (recordemos la insistencia de los intelectuales ilustrados en subrayar la importancia del empeño colectivo y del esfuerzo compartido), pero opta por un desenlace a la inversa, que hace naufragar deliberadamente toda empresa común de sus criaturas.

En lo que se refiere a las fábulas que funcionan como expresión del deseo de alejamiento del mundo por parte del sujeto, se trata de un apartado que traslada al mundo animal la práctica del apartamiento del mundo a través de una desvinculación de sí mismo, como efecto de la dificultad del sujeto para seguir siendo una "identidad social». David Le Breton -en su ensayo Disparaître de soi. Une tentacion contemporaine- define con el término "blancura" esta necesidad del individuo de tomar distancia de las expectativas que el contexto social nutre acerca del sujeto, y sostiene que la "blancura" es precisamente "la búsqueda de una relación matizada con los demás; es la resistencia que hay que oponer frente a los imperativos de construirse una identidad en el contexto del individualismo democrático de nuestras sociedades" (Le Breton 2015: 15)7. En las fábulas de Herra que pertenecen a este segundo grupo temático los animales presentan una "pasión por la ausencia", que se expresa en el deseo de no proponerse más hacia afuera.

Una perfecta y amarga parábola de la negación de sí mismo es la fábula «El abejón contra el vidrio" en la cual el narrador reflexiona con el lector sobre los motivos que inducen al abejón a golpearse sin cesar contra los cristales de una ventana, olvidando los golpes recibidos en sus precedentes intentos. La conclusión a la que llega el narrador es que uel abejón se estrella y torna a reventarse contra el cristal, porque lo enfurece la imagen que se refleja en él» (Herra 2011: 55). Este motivo de la auto-aniquilación frente a la imagen refleja representa la búsqueda de la máxima impersonalidad y neutralidad posibles, y está presente de forma recurrente en las reflexiones de Herra: el escritor costarricense pretende subrayar cómo la imagen del protagonista -al reflejarse en el espejo- transmite la necesidad de la negación del Yo, reflejado en el espejo.

7 Se ha tenido acceso al ensayo de Le Breton Disparaître de soi. Une tentacion contemporaine a través de la versión italiana de su trabajo, titulada Fuggire da sé. Una tentazione contemporanea. El texto de la cita en la versión italiana que se ha utilizado es el siguiente: “ll biancore [...] é la ricerca di un rapporto attenuato con gli altri: é la resistenza da opporre agli imperativi di costruirsi un'identitá nel contesto dell'individualismo democratico delle nostre societá". 
Ahora bien, puesto que el espejo es una herramienta que no se equivoca, y que reproduce tal como es al sujeto que en él se mira, cuando el espejo reproduce una imagen que el Yo no acepta y rechaza, el sujeto se encuentra entre una disyuntiva: o bien, hace todo lo posible por asegurar el triunfo de la imago que se ha ido construyendo de sí mismo, en oposición a la imagen reflejada; o bien, no es capaz de hacer prevalecer la imagen positiva e intenta desaparecer (en el caso del abejón, la desaparición coincide con la eliminación física del propio Yo).

En "Tristes cucarachas", la percepción de sí mismas que estos animales tienen provoca que se vean horrendas, que se perciban como rechazadas por parte de los otros animales y que sientan vergüenza por su imagen pública, por lo cual-concluye el papagayo/narrador- "si llega a sorprenderlas un rayo de luz, corren a ocultarse en las tinieblas, para no sufrir la humillación de que las miren" (Herra 2011: 25). Desde la perspectiva de las cucarachas, entendidas en este caso como un Yo colectivo, podría decirse que "necesito justificarme ante el ideal de objetividad de la imagen especular porque el otro tiene la potestad de juzgarme y se me presenta como tal" (Herra 2012: 25). Siguiendo esta línea interpretativa que propone la existencia de un juicio, es decir, de un Otro como juez, el conjunto de las cucarachas -como identidad colectiva homogénea en su sentir- lleva a cabo una verdadera denegación de su imagen según la perciben los otros.

En "La rata y las cucarachas", de nuevo, se plantea el motivo de la desaparición voluntaria de animales que buscan el máximo grado de transparencia social según una modalidad de ocultación deliberada que refleja el pensamiento de Michel Leiris cuando afirma que este tipo de desaparición es un "no existir más, ni de por sí, ni a través de intermediarios. Estar ya afuera del verbo ser, [...] haber tocado el punto rebelde a cualquier toponimia" (Leiris 1976: 249). En el cuento de Herra el punto de vista se desplaza al mundo de las cucarachas, quienes en una primera instancia observan cómo "la rata de los subsuelos llora su infortunio: ha oído decir que el pueblo animal la malquiere" (Herra 2011: 27) y poco después expresan su búsqueda de alejamiento del contexto social (esto es, la rebeldía a cualquier toponimia, según palabras de Leiris) reconociendo cómo "las cucarachas compartimos el desprecio del mundo, pero guardamos distancia" (Herra, 2011: 27).

En cuanto al tercer grupo, el de las fábulas que funcionan como relatos de condena de toda forma de vanidad y envanecimiento, cabe observar cómo los textos que integran este bloque están construidos a menudo según un esquema narrativo que presenta el castigo del vanidoso y del engreído como "resultado natural" de la ley del más fuerte. En este sentido, la agresividad congénita en el reino animal funcionaría en la praxis como una "condena perteneciente al estado de la naturaleza" de la vanidad del personaje-animal.

En "El gallo de oro", el rey indiscutido del gallinero se pasea "exhibiendo la cola dorada, la más hermosa del mundo, orgulloso y lleno de sín (Herra 2011: 62) y su figura 
majestuosa remite en un principio a la del rey de las fábulas, a la del monarca de un reino. Tradicionalmente, en las fábulas el hecho de convertirse en rey (o reina) de un reino apunta a un objetivo: "el de comandar en lugar de ser mandado. El ser que se convierte en rey o reina al final de la historia simboliza una condición de verdadera independencia, en la que el héroe se siente seguro, satisfecho y feliz" (Bettelheim 2015: $125)^{8}$.

$Y$ es en este punto donde la fábula de Herra quiebra -mediante un final que remite dura y cáusticamente a la ley del más fuerte- la integridad del esquema modélico: su rey del gallinero no logra alcanzar el estado de seguridad y felicidad, ni consigue una posición de verdadera independencia de los peligros inherentes a su condición de gallo, pues uun día llegaron los gavilanes y no perdonaron ni al gallo de oro ni a sus admiradoras" (Herra 2011: 62).

En "La libélula vanidosa", el motivo de la conversión de la protagonista en reina es más sutil pero igualmente concreto, puesto que este liderazgo se manifiesta en la presunta superioridad estética de la libélula, quien vuela con arte majestuoso y se imagina a los envidiosos del reino animal; durante sus ejercicios aéreos para lucirse ante los demás se jacta de tener "el cuerpo esbelto, las alas transparentes. Su belleza se inclina solo ante el milagro del colibrín (Herra 2011: 50).

Como se verá a continuación, en el desenlace Herra invierte el esquema del modelo canónico sobre la actuación del líder (rey, reina); para comprenderlo, cabe observar cómo "si algo se nos dice acerca del reino de esos reyes y reinas, es que fue sabio y pacífico [...]. La madurez debería consistir en la capacidad para gobernarse a sí mismos con sabiduría" (Bettelhein 2015: 126). La sabiduría y la sensatez son precisamente las cualidades cuya ausencia lleva al desenlace trágico, debido a que «a la urraca le importó poco la vanidad de la libélula cuando le dio un picotazo" (Herra 2011: 50).

En conclusión, las fábulas incluidas en La divina chusma se colocan en una dimensión literaria intermedia entre la mera revisitación del objetivo horaciano e ilustrado del prodesse et delectare al que se ha aludido en el primer apartado, y la gestación de un conjunto de fábulas en las que el afán didáctico y moralizador se difumina en un juego de espejos que parodia el modelo clásico y neoclásico.

Así como ocurre con las colecciones de fábulas de los ilustrados españoles, en la recopilación de Herra el prosaísmo le gana a la metáfora en nombre de un principio de utilidad que se remonta a la Poética de Ignacio de Luzán: se mantiene válida en La divina chusma la lógica neoclásica de uun empleo moderado del lenguaje figurado; la insistencia en que [la fábula] fuese al mismo tiempo útil y deleitable imponía evitar toda posibilidad de oscuridad de pensamiento" (Sotelo 2012: 55).

8 El texto italiano del ya citado ensayo de Bettelheim The use of enchantment. The meaning and importance of fairy tales es el siguiente: "Divengare re o regina di questo regno ha un solo scopo: quello di comadare anziché essere comandato. L'essere diventato un re o una regina alla conclusione della storia simboleggia una condizione di vera indipendenza, in cui l'eroe si sente sicuro, soddisfatto e felice". 
Por otro lado, se hace menos evidente en las fábulas del escritor costarricense la orientación pedagógica de la literatura: la tendencia ilustrada de educar al pueblo formando su sensibilidad se desplaza hacia la exhortación implícita a una reflexión introspectiva. Los animales que protagonizan las historias plantean sus vivencias al lector desde la perspectiva de una sencilla racionalidad en que conviven ironía, humor e incluso un matiz nostálgico, y es precisamente la aguda identificación por parte del autor de las analogías entre seres humanos y animales el elemento que permite que las fábulas lleguen a la esfera emotiva de los lectores.

\section{BIBLIOGRAFÍA}

Alvar, Carlos, José Carlos Mainer y Rosa Navarro. Breve historia de la literatura española. Madrid: Alianza Editorial. 2011. Impreso.

Bettelheim, Bruno. I/ mondo incantato. Uso, importanza e significati psicoanalitici delle fiabe. Milano: Feltrinelli Editore, 2015. Stampato.

Calabrese, Omar. L'etá neobarocca. Bari: Laterza, 1987. Stampato.

Cioranescu, Alejandro. "Sobre Iriarte, La Fontaine y fabulistas en general". Estudios de literatura epañola y comparada, 1954: 197-204. Impreso.

Hernández, Germán. "Rafael Angel Herra: La Divina Chusma». El Signo Roto. 2011. Web. 21 Oct. 2016.

Herra, Rafael Ángel. La divina chusma. San José de Costa Rica: Uruk Editores, 2011. Impreso.

- Autoengaño. Palabras para todos y sobre cada cual. San José de Costa Rica: Editorial UCR, 2012. Impreso.

Le Breton, David. Fuggire da sé. Una tentazione contemporanea. Milano: Raffaello Cortina Editore, 2016. Stampato.

Leiris, Michel. Frêle Bruit. Paris: Gallimard, 1976. Imprimé.

Lyotard, Jean-Francois. La condizione postmoderna. Milano: Feltrinelli, 1981. Stampato.

Propp, Vladimir. Morphologie du conte. Paris: Éditions Points, 2012. Imprimé.

Rodríguez Adrados, Francisco. Historia de la fábula greco-latina. 3 vols. Madrid: Editorial de la Universidad Complutense, 1979-1987. Impreso.

Samaniego, Félix María. Fábulas. Madrid: Cátedra, 2012. Impreso.

Sotelo I., Alfonso. “Introducción”. Samaniego, F.M, Fábulas, Madrid: Cátedra, 2012: 13-142. Impreso.

Fecha de recepción: 26 de octubre de 2016.

Fecha de aceptación: 11 de marzo de 2017. 